\title{
Foreign Body in Appendix Presenting As Acute Appendicitis- A Case Report
}

\author{
Dr. Anchal Chauhan ${ }^{1}$, Dr. Shashank Mishra ${ }^{2}$,Dr. Yash Pal Monga ${ }^{3}$, \\ Dr. Sumit Dutt Sharma ${ }^{4}$, Dr. Aditya Rastogi ${ }^{5}$, \\ ${ }^{I}$ Junior Resident III PG Dept.Of Surgery, Subharti Medical College, Meerut*Corresponding Author \\ ${ }^{2}$ Associate professor PG Dept. of Surgery, Subharti Medical College, Meerut \\ ${ }^{3}$ Professor PG Dept of Surgery, Subharti Medical College, Meerut \\ ${ }^{4}$ Senior Resident PG Dept of Surgery, Subharti Medical College, Meerut \\ ${ }^{5}$ Junior Resident II PG Dept.of Surgery, Subharti Medical College, Meerut
}

\begin{abstract}
Foreign bodies are rare causes of appendicitis and, in most cases, ingested foreign bodies pass through the alimentary tract asymptomatically. However, ingested foreign bodies may sometimes remain silent within the appendix for many years without an inflammatory response. Despite the fact that cases of foreignbody induced appendicitis have been documented, sharp and pointed objects are more likely to cause perforations and abscesses, and present more rapidly after ingestion. Blunt foreign bodies are more likely to remain dormant for longer periods and cause appendicitis through obstruction of the appendiceal lumen.
\end{abstract}

Keywords: foreign body, appendicitis

\section{Introduction}

Worldwide, appendicectomy for acute appendicitis is the most common emergency surgical procedure $[1,2]$. The ingestion of inedible and indigestible objects is frequent in children; in adults it is a rare condition that often occurs accidentally, or it can occur in patients with mental disorders or in prisoners [3, 4]. The presence of a foreign body (FB) in the appendix, acting as a cause of an inflammatory process, is a very rare event [5]. Here we present a rare case of an appendicectomy indicated for acute appendicitis with the part of LED bulb insitu.

\section{Case presentation-}

A 18-year-old male patient presented to our hospital with a 3 day history of colicky lower abdominal pain occasionally radiating to his right iliac fossa (RIF), which progressively increased in intensity over the last 1 day and localized to his RIF. He also gives a history of 1 episode of vomiting(vomitus containing food particles) and history of high grade fever since 1 day.

The patient had taken self-prescribed doses of diclofenac sodium with no relief. On examination, she had a temperature of $100{ }^{\circ} \mathrm{F}$, respiratory rate of 20 breaths per minute, pulse of 96 beats per minute, and his blood pressure was $116 / 82 \mathrm{mmHg}$. There was tenderness and guarding on palpation of his RIF and a positive Rovsing's sign. There was no palpable mass and his bowel sounds were sluggish. The rest of the examination was unremarkable. A white blood cell count showed a leucocytosis of 14,500 cells $/ \mathrm{mm} 3$. A working diagnosis of acute appendicitis was suggested with an Alvarado's score of 8/10. An abdominal ultrasound scan was requested which revealed a thickened appendiceal wall and fluid collection around her RIF. No FB was identified. He was prepared for emergency surgery. Via a gridiron incision, his appendix was delivered and was found to be perforated and on palpation, the appendix below the site of perforation was found to be unusually hard. And while palpating the hard object/ (?)foreign body was milked towards the perforated site and removed and on inspecting the foreign body it was found to be a part of a LED bulb. Appendix was ligated and removed his abdomen was closed in layers and drain was placed and kept in-situ for 3 days. The postoperative period was uneventful and he was discharged on postoperative day 5 . 


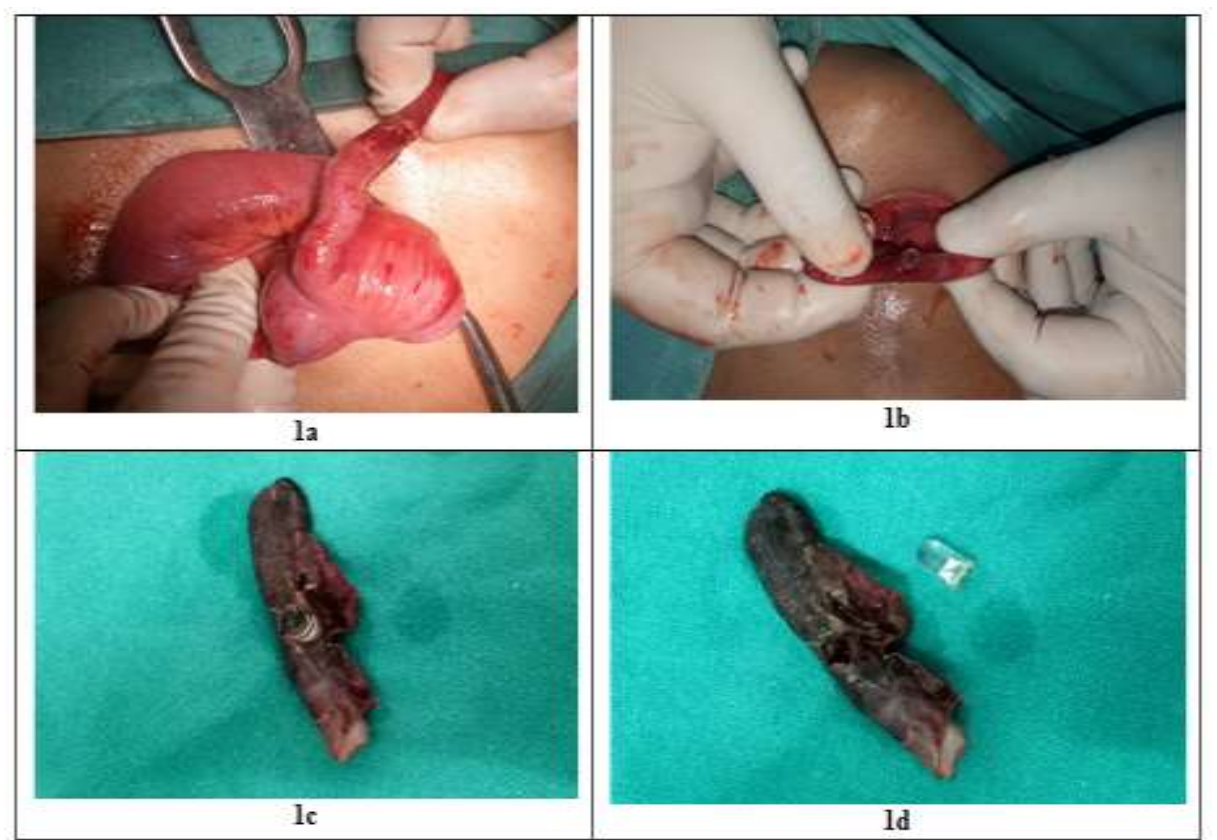

Fig.1- 1a- site of perforation in appendix, 1b- part of LED bulb milked out from site of perforation, 1c and 1dappendix with part of LED bulb

\section{Discussion}

The year 1735 saw the first appendicectomy, which was performed on an 11-year-old boy at St. George's Hospital in London by Claudius Amyand during which a sewing pin was found to have perforated the appendix [6]. FBs in the appendix are uncommon but well described with an estimated prevalence of $0.0005 \%$ $[7,8]$. FBs generally do not cause any complications and pass through the gastrointestinal tract (GIT) spontaneously within a week. The complication rate of ingested FBs is estimated at less than $1 \%$ [8]. A variety of objects are reported to be lodged in the appendix. The most common foreign bodies have been needles, pins, screws and buckshots. Ingested foreign bodies can remain immobile within the appendix for a long time without causing an inflammatory response or can cause an inflammatory reaction without causing perforation. The clinical findings range from asymptomatic to those of perforated appendicitis. In majority of cases, ingested foreign bodies pass through the alimentary tract without complication due to fecal coat around the foreign body [9]. Considering the dependent position of the cecum, foreign bodies tend to gravitate and stay in the caecum. In addition, the chance of entry to appendiceal lumen is determined not only by its orifice, but also by the anatomic position of the appendix. . Once the FB is lodged in the appendix, peristaltic motion is usually insufficient to expel it back into the cecal lumen. It may remain immobile in the appendix without stimulating an inflammatory process or cause an inflammatory reaction with or without perforation. The period of latency between ingestion of the FB and the onset of symptoms varies from hours to years $[4,10,11]$. Complications usually depend on the size and shape of the FB.

\section{Conclusions}

Foreign bodies are rare causes of appendicitis. A wide variety of objects can be trapped in the appendix. Our case demonstrates a rare clinical scenario in which an unusual FB became lodged in the appendix and eventually initiated an inflammatory process which resulted in acute appendicitis followed by perforation.

References

[1]. Chandrasegaram M, Rothwell L, An E, Miller R. Pathologies of the appendix: a 10-year review of 4670 appendicectomy specimens. ANZ J Surg. 2012;82: 844-7.

[2]. Sartelli M, Abu-Zidan F, Catena F, Griffiths E, Saverio S, Coimbra R, et al. Global validation of the WSES Sepsis Severity Score for patients with complicated intra-abdominal infections: a prospective multicentre study (WISS Study). World J Emerg Surg. 2015;10:61.

[3]. Hazer B, Dandin O, Karakaş D. A rare cause of acute appendicitis: an ingested foreign body. Ulus Travma Acil Cerr Derg. 2013;19(6):570-2.

[4]. Benizri E, Cohen C, Bereder J, Rahili A, Benchimol D. Swallowing a safety pin: report of a case. World J Gastrointest Surg. 2012;4:20-2.

[5]. Baek S, Bae O, Hwang I. Perforated appendicitis caused by foreign body ingestion. Surg Laparosc Endosc Percutan Tech. 2012;22:e94-97.

[6]. Amyand C. Of an inguinal rupture, with a pin in the appendix coeci, incrusted with stone; and some observations on wounds in the guts. Phil Trans Royal Soc. 1736;39:329. 
[7]. Balch C, Silver D. Foreign bodies in the appendix: report of eight cases and review of the literature. Arch Surg. 1971;102:14-20.

[8]. Klingler P, Seelig M, De Vault K, Wetscher G, Floch N, Branton S. Ingested foreign bodies within the appendix: A 100 year review of the literature. Dig Dis. 1998;16:308-14.

[9]. 9.Antonacci N, Labombarda M, Ricci C, Buscemi S, Casadei R, Minni F. A bizarre foreign body in the appendix: a case report. World J Gastrointest Surg 2013;5: 195-8

[10]. Song Y, Covarrubias D, Nardi P. Foreign body appendicitis. AJR Am J Roentgenol. 2009;193:W154-155.

[11]. Fischer C, Mukherjee A. Appendicitis due to tongue stud ingestion: a case study and review of management plans. S D J Med. 2004;57:19-22. 